\title{
Induction of immunoproteasomes in porcine kidney (PK)-15 cells by interferon- $\gamma$ and tumor necrosis factor-a
}

\author{
Qiang LIU1), Huai Yu WANG ${ }^{1)}$ and Xi-Jun HE')* \\ 1)Nanchong Key Laboratory of Disease Prevention, Control and Detection in Livestock and Poultry, \\ Nanchong Vocational and Technical College, Nanchong 637131, China \\ ${ }^{2)}$ State Key Laboratory of Veterinary Biotechnology, Harbin Veterinary Research Institute of Chinese Academy of \\ Agricultural Sciences, Harbin 150069, China
}

J. Vet. Med. Sci.

81(12): 1776-1782, 2019

doi: 10.1292/jvms.19-0157

Received: 21 March 2019

Accepted: 1 September 2019 Advanced Epub:

20 September 2019

\begin{abstract}
Immunoproteasome (i-proteasome) has both immune and non-immune functions and plays important roles in controlling infections and combating illnesses. Our previous studies suggest that interferon (IFN)- $\gamma$ induces the expression of three immune-specific catalytic subunits of the $20 \mathrm{~S}$ proteasome that can replace their constitutive homologues to form the i-proteasome in immune cells, such as porcine alveolar macrophages (AMs) in vitro. However, i-proteasome levels and their modulation in non-immune cells such as the epithelial cells in pigs remain unknown. Here, we investigated the expression of i-proteasomes in non-immune cells (porcine kidney (PK)15 cells) to determine i-proteasome modulation upon stimulation of PK-15 cells with IFN- $\gamma$ and tumor necrosis factor (TNF)- $a$ in vitro. The expression of i-proteasome subunits in PK-15 cells were regulated by IFN- $\gamma$ and TNF- $\alpha$. Remarkably, we found that the combination treatment of IFN- $\gamma$ and TNF- $a$ increased the expression of i-proteasome subunits LMP2, LMP7, and MECL-1 in PK-15 cells at transcriptional levels, but may decrease their expression at translational level, compared to their expression levels induced by individual cytokine treatments. These results provide critical insight into i-proteasome modulation in porcine non-immune cells, contribute further to our understanding of i-proteasome function in tissue pathogenesis and the development of antiviral adaptive immune responses against intracellular infections.
\end{abstract}

KEY WORDS: epithelial cell, immunoproteasome, interferon- $\gamma$, pig, tumor necrosis factor- $a$

Proteasomes are large, intracellular, multicatalytic, proteinase complexes responsible for degrading ubiquitinated proteins in jawed vertebrates and play a critical role in homeostasis and immunity [18]. The central proteolytic unit of this system is the 20S proteasome, which has a barrel-shaped structure comprising four heteroheptameric rings with seven subunits each. The two pairs of outer $\alpha$ rings are composed of seven $\alpha$-type structural subunits $(\alpha 1-\alpha 7)$, whereas the two pairs of inner $\beta$ rings are composed of seven $\beta$-type structural subunits ( $\beta 1-\beta 7$ ), three of which (namely $\beta 1$, also known as PSMB6, Y, and $\delta$; $\beta 2$, also known as PSMB7, $\mathrm{Z}$, and MC14; and $\beta 5$, also known as PSMB5, $\mathrm{X}, \mathrm{MB} 1$, and $\varepsilon$ ) exhibit proteolytic activity, including caspase-like activity for $\beta 1$, trypsin-like activity for $\beta 2$, and chymotrypsin-like activity for $\beta 5$. The two $19 \mathrm{~S}$ regulatory complex components located at both ends of the $20 \mathrm{~S}$ core proteasome recognize ubiquitinated proteins and direct them into the core of the 20S core proteasome, where they are degraded into smaller peptides by proteolysis [12]. Cells of hematopoietic origin and those stimulated with proinflammatory factors, such as interferon (IFN)- $\gamma$, demonstrate upregulation of these three inducible "immunosubunits" including $\beta 1 \mathrm{i}$ (also known as large multifunctional peptidase (LMP) 2 or proteasome subunit beta type (PSMB) 9), $\beta 2 \mathrm{i}$ (also known as LMP10, multicatalytic endopeptidase complex-like (MECL)-1, or PSMB10), and $\beta 5$ i (also known as LMP7 or PSMB8), which replace the three $\beta$ subunits $(\beta 1, \beta 2$, and $\beta 5$ ) of the 20 S proteasome. This proteasome with the modified $\beta$ subunits is known as the immunoproteasome (i-proteasome). Evidence suggests that peptides generated by the i-proteasome are both distinct from and more efficient at CTL activation in comparison to those generated by the constitutive proteasome [27].

I-proteasomes exhibit both immune and non-immune functions and play an important role in controlling infections and combating illnesses. One study demonstrated reduced T cell repertoire, including CD8+ T-cell counts, in LMP2 ${ }^{-/-}$mice in comparison to wild-type (C57BL/6) control mice [4]. Another study reported that inhibition of the i-proteasome subunit LMP7 resulted in decreased IFN- $\gamma$ production and reduced differentiation of naïve CD4+ T-cells into T helper cell (Th)-17 cells [24].

*Correspondence to: He, X.-J.: hexijun@caas.cn

(Supplementary material: refer to PMC https://www.ncbi.nlm.nih.gov/pmc/journals/2350/)

(O2019 The Japanese Society of Veterinary Science

This is an open-access article distributed under the terms of the Creative Commons Attribution Non-Commercial No Derivatives (by-nc-nd) License. (CC-BY-NC-ND 4.0: https://creativecommons.org/licenses/by-nc-nd/4.0/) 
These findings suggest that the i-proteasome is functionally involved in the generation of the T cell repertoire, regulation of the pro-inflammatory cytokine production, and controls Th cell differentiation. I-proteasome was also reported to be upregulated in prostate cancer, multiple myeloma, and lung cancer, but another report confirmed that i-proteasome expression was downregulated in cancers of the colon, kidney, skin, neck, head, and esophagus [23]. These results suggested that the variation in the expression of i-proteasomes is attributed to the different types of cancers. Collectively, these studies provide a greater understanding of the role of the i-proteasome system in the overall health and well-being of the host. For instance, changes in proteasome subunit composition and expression observed in the different mammalian tissues are closely associated with various autoimmune disorders, inflammatory diseases, and cancers in both humans and mice. However, the expression pattern and composition of the i-proteasome is poorly studied in various tissues of other species such as pigs.

Previous studies in our laboratory suggested that the i-proteasomes expression is markedly altered in the porcine lung and thymus upon infection with porcine reproductive and respiratory syndrome virus (PRRSV). In vitro assays further confirmed that the expression of i-proteasomes is increased in IFN- $\gamma$-stimulated primary alveolar macrophages (AMs) [20]. However, the AMs were identified as only one cell type to readily express low levels of i-proteasome subunits. The i-proteasome subunits expression confined to the cytoplasm and nucleus in AMs under normal conditions. In addition, i-proteasome expression could also be detected in other lung parenchymal cells including alveolar type I and II cells, bronchial epithelial cells in the lung, and epithelial cells in the thymus of PRRSV-infected pigs $[19,20]$. However, expression of the i-proteasome in other non-immune cells of pigs has not been reported, and little is known about the levels of proteasome subpopulations and their modulation in non-immune cells such as epithelial cells. In the present study, we used porcine kidney (PK)-15 cells, an epithelial cell model susceptible to many viral infections in pigs, to determine the i-proteasome expression in PK-15 upon in vitro stimulation of these cells with IFN- $\gamma$ and TNF- $\alpha$. A better understanding of the role of the i-proteasome in different cell types, tissues, and hosts would facilitate the development of antiviral adaptive immune responses against intracellular infections.

\section{MATERIALS AND METHODS}

\section{Cell culture and IFN- $\gamma$ or TNF- $\alpha$ treatment}

PK-15 cells were cultured in 6-well plates (Corning, Ithaca, NY, U.S.A.) at an appropriate density in Dulbecco's Modified Eagle Medium (DMEM; Gibco, Carlsbad, CA, U.S.A.) supplemented with 10\% heat-inactivated fetal bovine serum (FBS; Gibco), 100 $\mathrm{U} / \mathrm{m} l$ penicillin, and $100 \mu \mathrm{g} / \mathrm{m} l$ streptomycin, at $37^{\circ} \mathrm{C}$ in a $5 \% \mathrm{CO}_{2}$ humidified incubator. Cells were stimulated with different concentrations of IFN- $\gamma$ including 2,000, 1,000, 500, and $250 \mathrm{ng} / \mathrm{m} l$ and TNF- $\alpha$ including 1,000, 500, 250, 50, and $5 \mathrm{ng} / \mathrm{ml}$. To evaluate the effects of cytokines on the growth of PK-15 cells in vitro, cell viability of these cells were examined under the respective optimized concentrations mentioned above, using cell counting kit 8 (CCK-8; Beyotime Biotechnology, Beijing, China) in accordance with the manufacturer's instructions. Furthermore, to assess the i-proteasome expression upon cytokine stimulation, after culturing for $24 \mathrm{hr}$, PK-15 cells were treated with either 1,000 $n \mathrm{~g} / \mathrm{m} l \mathrm{IFN}-\gamma$ (Sigma-Aldrich, St. Louis, MO, U.S.A.), or 500 $n \mathrm{~g} / \mathrm{m} l \mathrm{TNF}-\alpha$ (Sigma-Aldrich) separately, or with a combination of TNF- $\alpha(500 \mathrm{ng} / \mathrm{m} l)$ and IFN- $\gamma(1,000 \mathrm{ng} / \mathrm{m} l)$. Cell culture medium alone was used as a negative control. Cells were harvested with a cell scraper at 6, 12, 24, 36 and $48 \mathrm{hr}$ after stimulation. The expression of i-proteasome subunits LMP2, LMP7, MECL-1, and $\alpha 5$ was determined at the mRNA and protein level by quantitative reverse transcription PCR (RT-qPCR) and western blotting, respectively.

\section{$R T-q P C R$ analysis}

RNA was extracted using Trizol reagent (Invitrogen, Carlsbad, CA, U.S.A.). About $1 \mu \mathrm{g}$ of total RNA was reverse transcribed using the reverse transcription system kit (Takara, Kusatsu, Japan) by following the manufacturers' instructions. Relative gene expression was determined using the SYBR Green Kit (Takara). The sense and antisense primers for target genes are listed in Supplementary Table 1 . Amplification conditions were as follows: $50^{\circ} \mathrm{C}$ for $2 \mathrm{~min}, 90^{\circ} \mathrm{C}$ for $10 \mathrm{~min}$, with 40 cycles of $95^{\circ} \mathrm{C}$ for $30 \mathrm{sec}, 55^{\circ} \mathrm{C}$ and $72^{\circ} \mathrm{C}$ for $30 \mathrm{sec}$ each, with a final incubation at $4^{\circ} \mathrm{C}$. Gene expression was normalized to the mRNA content of glyceraldehyde-3-phosphate-dehydrogenase (GAPDH), and the results were presented as fold-change values for IFN- $\gamma$ and TNF- $\alpha$ (alone or in combination) for the treated group relative to the control group and were calculated using the $2^{-\Delta \Delta C T}$ method [1].

\section{Western blotting}

Treated and untreated PK-15 cells were harvested and lysed in RIPA lysis solution (Beyotime Biotechnology). Lysates were then prepared and immunoblotted with antibodies against LMP2, LMP7 (Abcam, Cambridge, U.K.), MECL-1 (Abcam), $\alpha 5$ (Abcam), and $\beta$-actin (Abcam). Signal were visualized using the DyLight ${ }^{\mathrm{TM}} 800$ goat anti-rabbit or mouse IgG (H+L) (KPL, MA, U.S.A.) secondary antibody diluted at 1/10,000 in PBS, for $40 \mathrm{~min}$. Bands were visualized using the Odyssey Imaging System (Li-cor Biosciences, Lincoln, NE, U.S.A.). The expression level of i-proteasome subunits relative to that of $\beta$-actin was quantified using the Image-J software (NIMH, Bethesda, MD, U.S.A.).

\section{Statistical analysis}

All experiments were performed at least in triplicates and statistical analysis of data was performed using the Mann-Whitney test to compare the RT-qPCR results. The results were considered statistically significant or very significant when $P$ values were less than 0.05 or 0.01 , indicated by * or **, respectively. All the analyzed graphs were constructed using GraphPad Prism (Version 7.02, GraphPad Software, San Diego, CA, U.S.A.). 
A

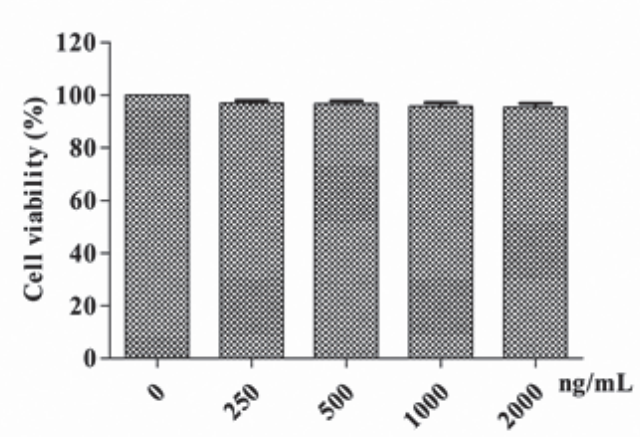

C

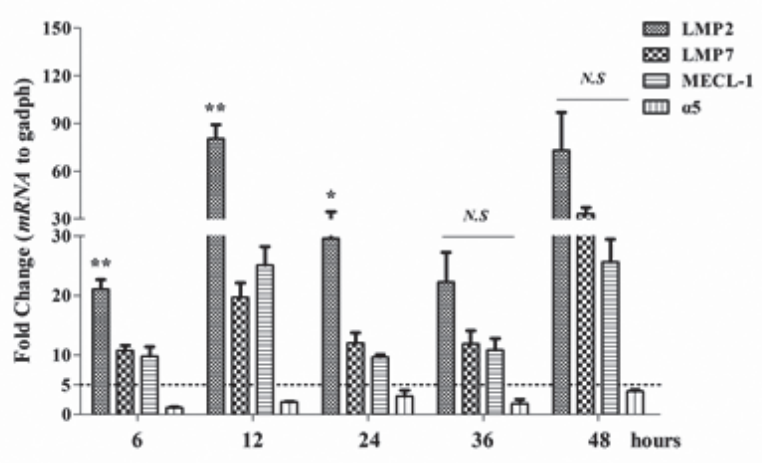

D
B

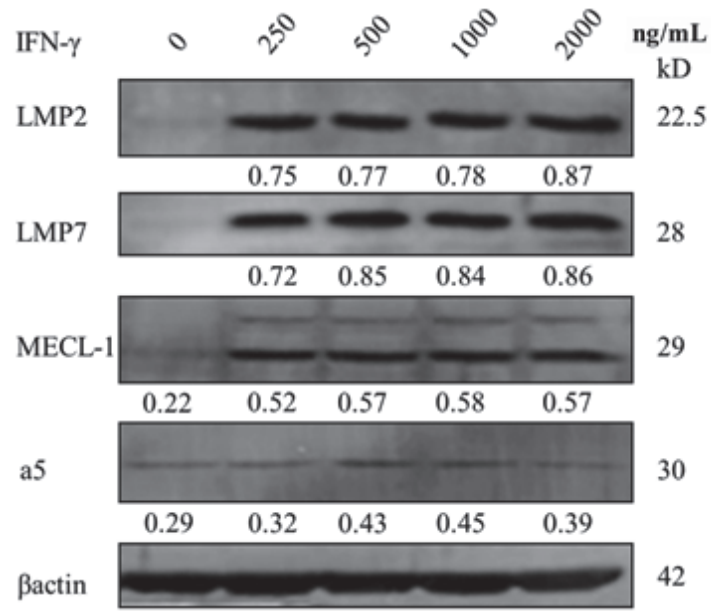

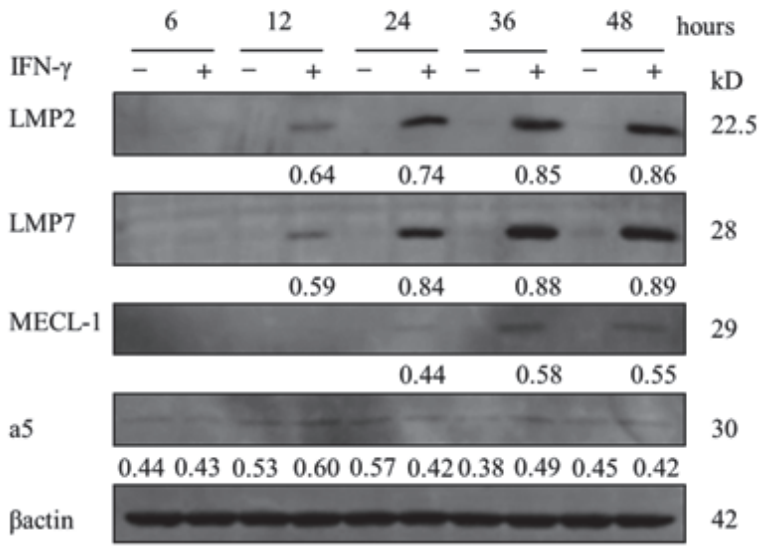

Fig. 1. Expression of i-proteasome subunits in porcine kidney (PK)-15 cells exposed to interferon (IFN)- $\gamma$. Optimization of IFN- $\gamma$ concentrations for stimulation. (A) Viability of PK-15 cells treated with different concentration of IFN- $\gamma$. To evaluate the effects of IFN- $\gamma$ on the growth of the PK-15 cells, a cell viability assay was carried out using cell counting kit 8 (CCK-8) according to the manufacturer's instructions. (B) Cells were stimulated with IFN- $\gamma$ at different stimulation concentrations including $2,000,1,000,500,250$, and $0 \mathrm{ng} / \mathrm{ml}$. The protein expression of LMP2, LMP7, MECL-1, and $\alpha 5$ was assessed in PK-15 cells treated with IFN- $\gamma$ for 24 hr, by western blotting. Numbers indicate densitometric analyses. (C) Relative fold changes of mRNA expression of i-proteasome subunits LMP2, LMP7, and MECL-1, and $\alpha 5$ in IFN- $\gamma$ treated PK-15 cells were compared to that of untreated cells. Cells were treated with IFN- $\gamma$ for different time durations. Results are representative of three independent experiments. $* P<0.05$, $* * P<0.01$. (D) The protein expression of LMP2, LMP7, MECL-1, and $\alpha 5$ was assessed in IFN- $\gamma$ treated PK-15 cells by western blotting. Numbers indicate densitometric analyses.

\section{RESULTS}

\section{IFN- $\gamma$ induces the expression of immunoproteasome-coding genes in PK-15 cells}

To analyze the i-proteasome expression in porcine epithelial cells upon IFN- $\gamma$ stimulation, PK-15 porcine epithelial cells, which are susceptible to numerous viral infections $[2,34]$, were selected and stimulated with or without IFN- $\gamma$ from 6 to $48 \mathrm{hr}$. IFN- $\gamma$ exerted no significant effect on cell viability at 2,000, 1,000, 500, and $250 \mathrm{ng} / \mathrm{ml}$ (Fig. 1A) and 1,000 $\mathrm{ng} / \mathrm{ml}$ was selected for cellular stimulation after treatment (Fig. 1B). The mRNA expression levels of the i-proteasome subunit LMP2 increased after $6 \mathrm{hr}$ of IFN- $\gamma$ treatment and reached a maximum level after $12 \mathrm{hr}$ of IFN- $\gamma$ treatment (Fig. 1C). In contrast, LMP7 and MECL-1 levels were sustained up to a maximum level at $48 \mathrm{hr}$. However, $\alpha 5$, which is an indicator of total proteasome levels, was sustained at a low level regardless of IFN- $\gamma$ treatment time. Among the genes that were differentially regulated in IFN- $\gamma$ treated PK-15 cells, LMP2 expression was significantly upregulated in comparison to that of LMP7 and MECL-1 after 6 to $24 \mathrm{hr}$ of IFN- $\gamma$ treatment $(P<0.05)$. After $24 \mathrm{hr}$, no differences were observed among the expression levels of LMP2, LMP7, and MECL-1 ( $P>0.05)$. However, the expression of all three i-proteasomes subunits was markedly higher than that of $\alpha 5$ after IFN- $\gamma$ stimulation of PK-15 cells from 6 to $48 \mathrm{hr}(P<0.05)$ (Fig. 1C). We further determined the protein levels of the LMP2, LMP7, MECL-1, and $\alpha 5$ in PK-15 cells that were untreated with or treated with IFN- $\gamma$ at $1,000 \mathrm{ng} / \mathrm{ml}$. In comparison to the untreated PK-15 cells, the protein levels of LMP2, LMP7, and MECL-1 elevated significantly in IFN- $\gamma$-treated PK-15 cells in a time-dependent manner (Fig. 1D). However, $\alpha 5$ was sustained at low level regardless of the time after IFN- $\gamma$ treatment (Fig. 1D). Taken together, these results indicate that IFN- $\gamma$ induces the expression of all three i-proteasomes subunits LMP2, LMP7, and MECL-1 at both the mRNA and protein levels in PK-15 cells. 
A

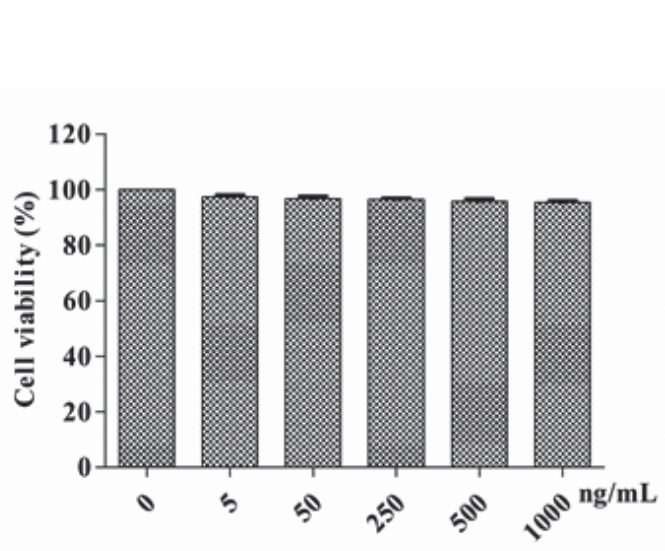

B

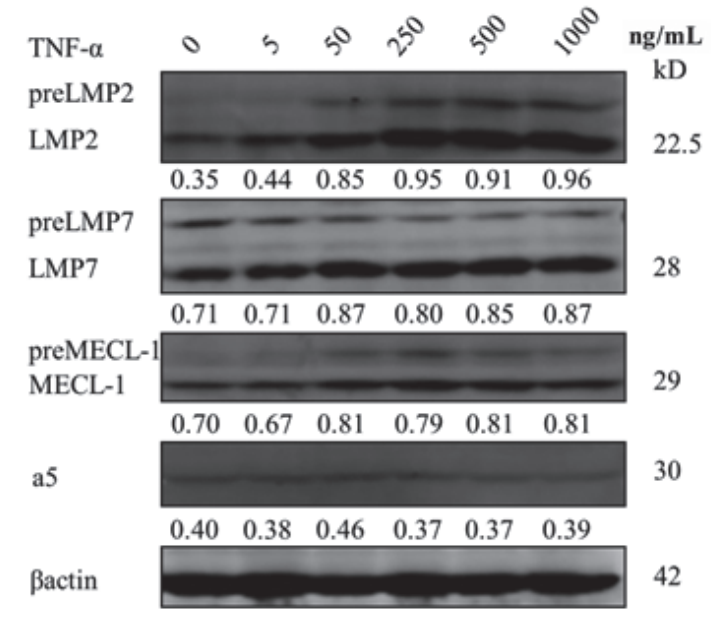

C

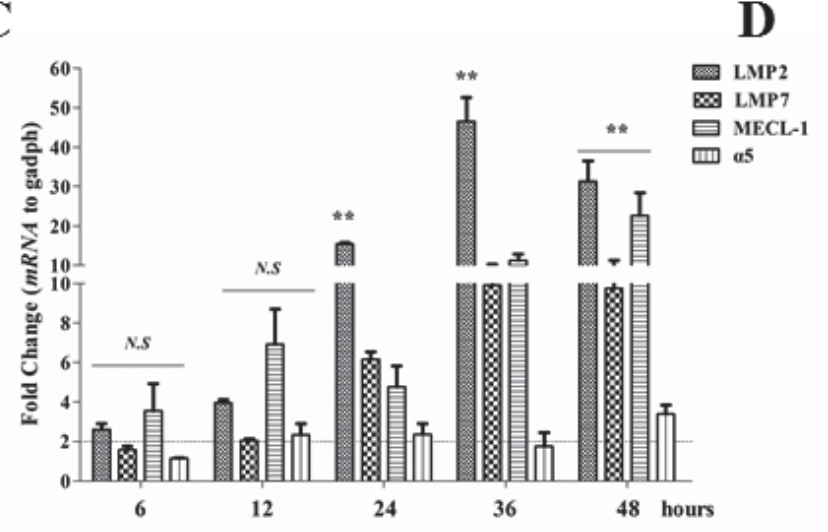

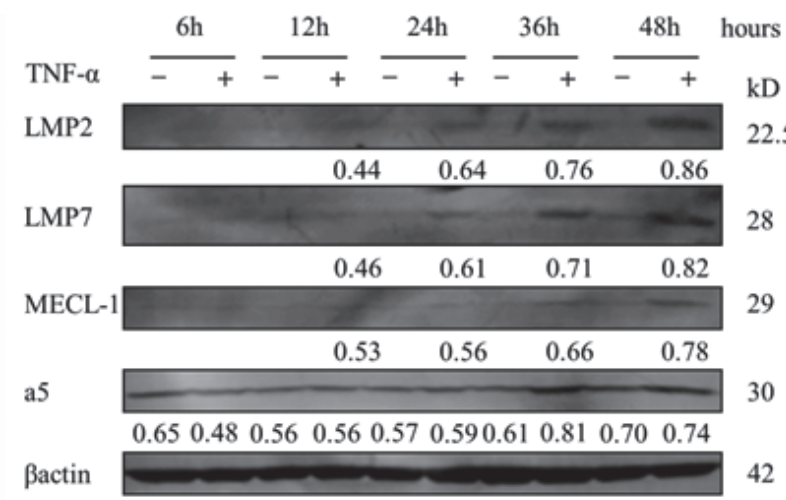

Fig. 2. Expression of i-proteasome subunits in porcine kidney (PK)-15 cells exposed to tumor necrosis factor (TNF)- $\alpha$. Optimization of TNF- $\alpha$ concentrations for stimulation. (A) Viability of PK-15 cells treated with different concentration of TNF- $\alpha$. To evaluate the effects of TNF- $\alpha$ on the growth of the PK-15 cells, a cell viability assay was carried out using cell counting kit 8 (CCK-8) by following the manufacturer's instructions. (B) Different stimulation concentrations including 1,000, 500, 250, 50, 5, and $0 \mathrm{ng} / \mathrm{m} l$ for TNF- $\alpha$ were selected. The protein expression of LMP2, LMP7, MECL-1, and $\alpha 5$ was assessed in PK- 15 cells exposed to TNF- $\alpha$ for 24 hr by western blotting. Numbers indicate densitometric analyses. (C) Relative fold changes of mRNA expression of i-proteasome subunits LMP2, LMP7, and MECL-1, and $\alpha 5$ in TNF- $\alpha$ treated PK-15 cells were compared to that of untreated cells. PK-15 cells were treated with TNF- $\alpha$ for different time durations. Results are representative of three independent experiments. ${ }^{*} P<0.05$, ${ }^{*} P<0.01$. (D) The protein expression of LMP2, LMP7, MECL-1, and $\alpha 5$ was assessed in PK-15 cells treated with TNF- $\alpha$ by western blotting. Numbers indicate densitometric analyses.

\section{TNF- $\alpha$ induces the expression of immunoproteasome-coding genes in PK-15 cells}

The level of IFN- $\gamma$ and TNF- $\alpha$ were significantly increased in the inflamed regions of the HP-PRRSV-infected-lung in comparison to their levels in normal lung [8]. We next assessed the effect of another proinflammatory cytokine (TNF- $\alpha$ ) on the expression of i-proteasome subunits LMP2, LMP7, and MECL-1 in PK-15 cells with or without TNF- $\alpha$ stimulation from 6 to $48 \mathrm{hr}$. The different TNF- $\alpha$ stimulation concentrations including 1,000, 500, 250, 50, and $5 \mathrm{ng} / \mathrm{m} l$ did not significantly influence cell viability (Fig. 2A), and $500 \mathrm{ng} / \mathrm{m} \mathrm{l}$ was selected for subsequent cellular treatments (Fig. 2B). TNF- $\alpha$ treatment significantly increased the mRNA levels of all three i-proteasome subunits, LMP2, LMP7, and MECL-1 in the PK-15 cells in a time-dependent manner (Fig. 2C). LMP2 expression increased in TNF- $\alpha$ treated Pk-15 cells after $6 \mathrm{hr}$ in comparison to that in cells without TNF- $\alpha$ treatment, and their expression levels reached a maximum at $36 \mathrm{hr}$ in TNF- $\alpha$ treated PK-15 cells. In contrast, LMP7 and MECL-1 levels were sustained at the maximum level for up to $48 \mathrm{hr}$. However, $\alpha 5$ was sustained at a low level regardless of the time period for which TNF- $\alpha$ treatment was administered. Among the differentially regulated genes, the expression of LMP2 was significantly upregulated in comparison to LMP7 and MECL-1 in TNF- $\alpha$ treated PK-15 cells at 24 to $36 \mathrm{hr}(P<0.05)$. No differences were observed in the expressions of the three i-proteasome subunits LMP2, LMP7, and MECL-1 in TNF- $\alpha$ treated PK-15 cells from 6 to $12 \mathrm{hr}(P>0.05)$. However, the expression levels of all three i-proteasome subunits were markedly higher than that of $\alpha 5$ in PK-15 cells after TNF- $\alpha$ stimulation from 24 to $48 \mathrm{hr}(P<0.05)$ (Fig. 2C). At the protein level, LMP2, LMP7, and MECL-1 were significantly upregulated in PK-15 cells upon TNF- $\alpha$ treatment in a time-dependent manner, in comparison to that of the untreated cells (Fig. 2D). $\alpha 5$ was also increased in a time-dependent manner regardless of TNF- $\alpha$ treatment, but to a lesser extent (Fig. 2D). Taken together, these results are consistent with our RT-qPCR results and indicate that TNF- $\alpha$ induces the expression of 

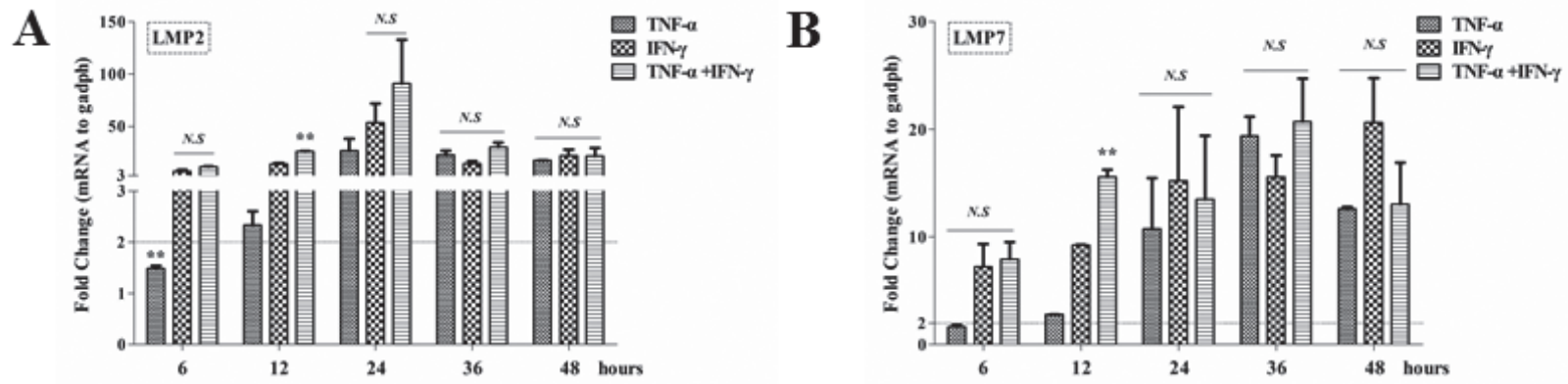

C

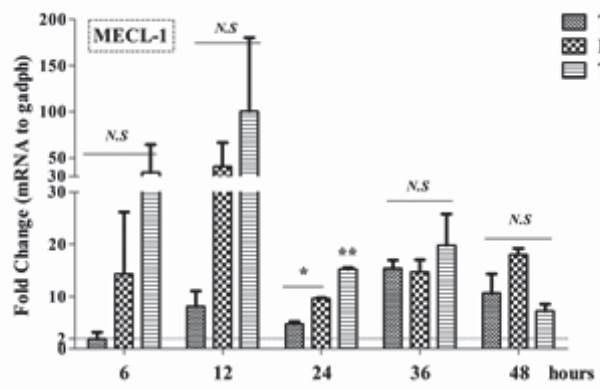

D
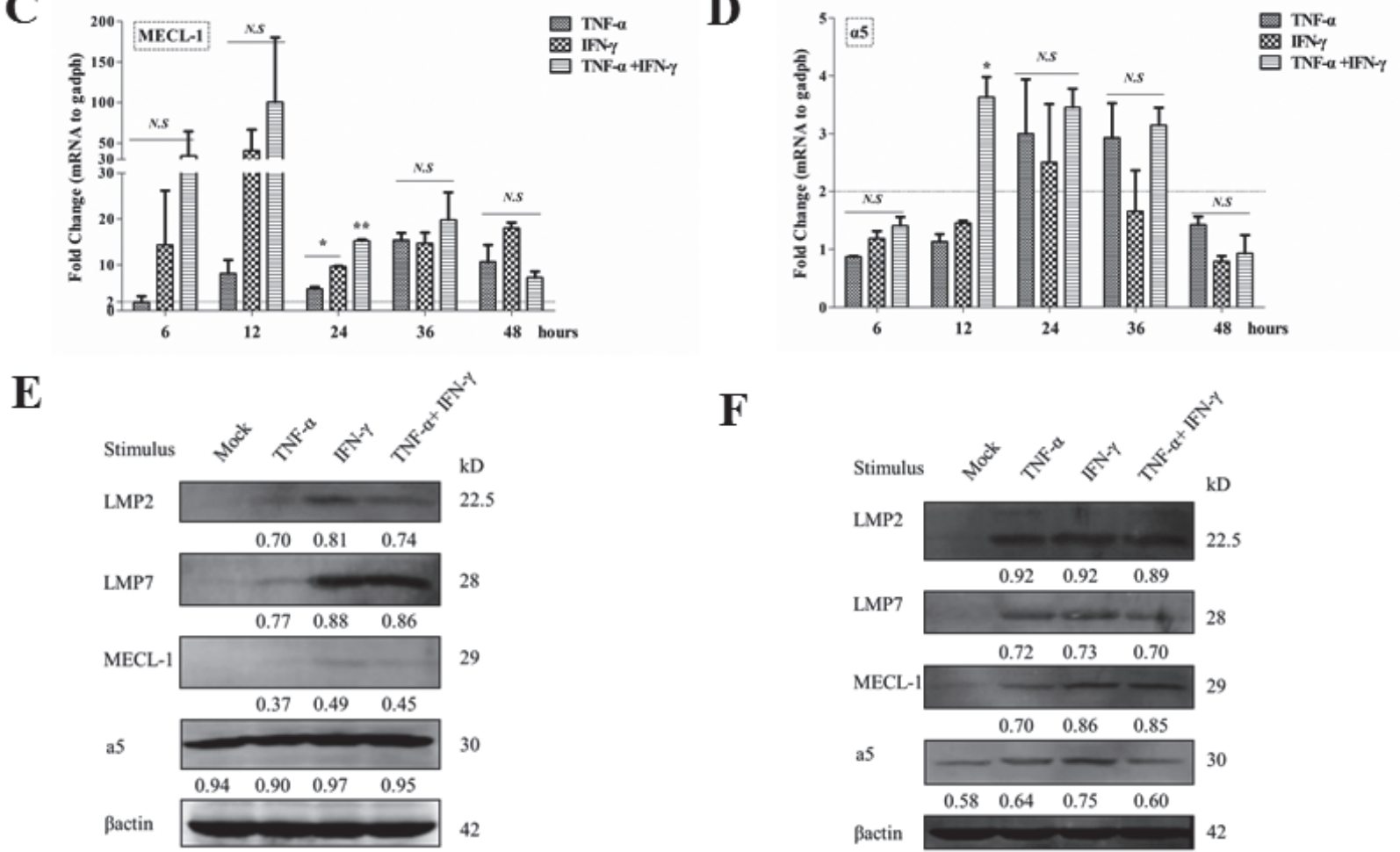

Fig. 3. Porcine kidney (PK)-15 cells were treated with a combination of tumor necrosis factor (TNF)- $\alpha$ and interferon (IFN)- $\gamma$ for $6-48 \mathrm{hr}$. Relative fold changes of mRNA expression for i-proteasome subunits LMP2 (A), LMP7 (B), MECL-1 (C) and $\alpha 5$ (D) in TNF- $\alpha$ and IFN- $\gamma$ treated cells were compared to that of untreated cells. Cell were treated with TNF- $\alpha$ and IFN- $\gamma$ for $6-48$ hr. Results are representative of three independent experiments. $* P<0.05$, $* * P<0.01$. The protein expression of LMP2, LMP7, MECL- 1 , and $\alpha 5$ was assessed in PK-15 cells exposed to TNF- $\alpha$ plus IFN- $\gamma$ for $24 \mathrm{hr}(\mathrm{E})$ or $48 \mathrm{hr}(\mathrm{F})$ by western blotting. Numbers indicate densitometric analyses.

i-proteasome subunits LMP2, LMP7, and MECL-1 in PK-15 cells at both the transcriptional and translational levels.

\section{Proinflammatory cytokines induce immunoproteasomal expression in PK-15 cells}

Collectively, the above data demonstrate that i-proteasome subunits are induced by IFN- $\gamma$ as well as TNF- $\alpha$. We further assessed the combined effect of these cytokines on i-proteasomal expression. PK-15 cells were exposed for 6-48 hr, either separately to IFN- $\gamma$ and TNF- $\alpha$, or to a combination treatment of these two cytokines. The expression level of i-proteasome subunits LMP2, LMP7, and MECL-1 was then quantified. At the mRNA level, in comparison to individual cytokine treatments, the combination treatment of both the cytokines induced a significant increase $(P<0.05)$ in LMP2 (Fig. 3A) and LMP7 (Fig. 3B) expression, but not in MECL-1 (Fig. 3C) expression, which sustained for up to $24 \mathrm{hr}$ in PK-15 cells. The level of $\alpha 5$ also increased till $24 \mathrm{hr}$, although to a lesser extent, regardless of the nature of the treatments, (Fig. 3D). In addition, at the protein level, $24 \mathrm{hr}$ exposure to the combination IFN- $\gamma$ plus TNF- $\alpha$ induced an increase in the expression of i-proteasome subunits LMP2, LMP7, and MECL-1, but these expression levels were lower than those with the individual cytokine treatment (Fig. 3E). A similar induction pattern was observed in PK-15 cells treated for $48 \mathrm{hr}$ with the cytokine combination and individual cytokines (Fig. 3F).

\section{DISCUSSION}

I-proteasome-mediated protein cleavage plays important roles in controlling cell functions including cell growth, differentiation, 
metabolism, and immune regulation [25]. In this study, we examined the role of i-proteasomes in non-immune cells (porcine kidney cells in vitro) based on their expression and modulation during pro-inflammatory cytokines stimulation. The results of this study demonstrates for the first time that the expression of i-proteasome subunits in porcine epithelial cells (such as PK-15) is regulated by IFN- $\gamma$ as well as TNF- $\alpha$. Importantly, our studies indicate that in comparison to treatment with individual cytokines, the combination treatment of IFN- $\gamma$ plus TNF- $\alpha$ increases the expression of i-proteasome subunits LMP2, LMP7, and MECL-1 in PK-15 cells at the transcriptional level, but decreases their expression at the translational level. These results provide critical insight into the expression of i-proteasomes in non-immune cells, which contributes further to our understanding of the functions of i-proteasome in tissue pathogenesis.

IFN- $\gamma$ is a well-known strong inducer of i-proteasomes in humans and mice [13]. The cytokine IFN- $\gamma$ is mainly synthesized by activated $\mathrm{T}$ lymphocytes and natural killer cells and has pleiotropic effects on the growth, differentiation, and development of different tissues [6]. The receptors for IFN- $\gamma$ are mostly expressed on hematopoietic cells (NK, NKT, Th1, and CTL cells) [28]. Our previous study confirmed that cultured immune cells such as AMs could upregulate the expression of i-proteasome subunits upon in vitro stimulation with IFN- $\gamma$ [20]. Several studies have reported the expression of IFN- $\gamma$ receptor on A549 cells originating from alveolar epithelium [29]. Induction of i-proteasome subunit expression by IFN- $\gamma$ has been well established in vitro with cultured retinal epithelial cells [14]. Induction of i-proteasomes in various cells likely occurs due to the persistent activation of IFN intracellular signaling pathways. Binding of transcription factors such as STAT-1 and IRF-1 to multiple IFN- $\gamma$ activation sequences in the promoter region of i-proteasome subunits including LMP2, LMP7, and MECL-1 triggers their upregulation [7].

TNF- $\alpha$ is mainly secreted by macrophages, and its receptors are present on most cell types, including epithelial cells [31]. The binding of TNF- $\alpha$ to their receptors causes activation of the NF- $\kappa$ B or MAPK pathways, which mediate the transcription of a vast array of genes involved in cell survival, differentiation and proliferation, inflammatory response, and apoptotic process (antiapoptotic and pro-apoptotic factors) [33]. Several studies have confirmed that i-proteasomes impaired the NF- $\mathrm{kB}$ activation in lymphocytes from $\beta \mathrm{li}^{-/-}$mice [16] as well as in $\beta \mathrm{li}^{--}$and $\beta 5 \mathrm{i}^{-/-} \mathrm{T} 2$ human lymphocyte cell lines but did not do the same in their parental T1 cell line [17]. These results suggest that i-proteasomes play an important role in TNF- $\alpha$-induced apoptosis through modulation of the NF- $\mathrm{KB}$ pathway. Some studies on i-proteasome induction by TNF- $\alpha$ in non-immune cells report contradictory results. A study showed that i-proteasomes are expressed in human tumor cells of non-hematological origin following induction by cytokines including IFN- $\gamma$ or TNF- $\alpha$ [11]. However, another study demonstrated that three murine cell lines of non-hematopoietic origin almost exclusively expressed constitutive proteasomes, whereas the expression of i-proteasomes could be induced in such cells following their exposure to IFN- $\gamma$, but not to TNF- $\alpha$ [5]. In this study, we observed that the i-proteasome subunits LMP2, LMP7, and MECL-1 could be induced by TNF- $\alpha$ treatment in PK-15 cells, though less efficiently than that inducible by IFN- $\gamma$ at both transcriptional and translational levels. These contradictory results are probably due to differences in the species. The complete pig genome is available online, and data regarding the comparison of mouse, human, and pig immune systems have revealed that the immune system of pigs more closely resembles that of humans than that of mice [10]. In addition, the concentration and duration of cytokines stimulation, cell populations, and phenotypes should also be considered in the context of these contradictory results.

An initial study reported that TNF- $\alpha$ acts synergistically with IFN- $\gamma$ to upregulate i-proteasome subunit $\beta 5 \mathrm{i}$ [15], implying that other pro-inflammatory cytokines combined with IFN- $\gamma$ may regulate i-proteasome. Previous results and the present results suggest that the i-proteasome can be induced by IFN- $\gamma$ in porcine immune cells, such as AMs and dendritic cells (DCs), and in porcine non-immune cells such as epithelial cells; in addition it can also be induced by TNF- $\alpha$ in non-immune cells in vitro. These results are concurrent with those of previous reports on marked upregulation of i-proteasomes in PRRSV-infected lung parenchymal cells, wherein IFN- $\gamma$ and TNF- $\alpha$ are consistently and robustly expressed in the inflamed regions in the lung [8]. In addition, in comparison to the effect of individual cytokine treatments, enhanced effects were observed for combination treatments of IFN- $\gamma$ and TNF- $\alpha$, on the expression of i-proteasome subunits LMP2, LMP7 and MECL-1 at the transcriptional level. Although the precise mechanism underlying the enhanced effects of the combination treatments of IFN- $\gamma$ and TNF- $\alpha$ is unclear at the transcriptional level, this enhancement may have resulted from the increase in the number of TNF- $\alpha$ receptors induced by IFN- $\gamma$, as observed in numerous cell types $[3,32]$. Furthermore, our results show that IFN- $\gamma$ and TNF- $\alpha$, alone or in combination, differentially regulated the synthesis of the i-proteasome subunits LMP2, LMP7, and MECL-1 at the translational level, and these effects were mediated by post-transcriptional and post-translational regulatory mechanisms. Protein synthesis occurs in a multiple ribosomal structure called a polyribosome [9]. In Cap-dependent translation, the ribosome identifies the translation initiation site by sliding along the mRNA or in the Cap-independent translation, the ribosome directly enters the interior of the mRNA by recognizing a particular internal ribosome entry site (IRES). The ribosome complex in eukaryotic cells tightly regulates the intricate events including translational initiation, mRNA scanning and protein elongation [9]. One robust method to interfere with protein synthesis is to regulate ribosome abundance and composition and to interfere ribosome interaction with specific mRNAs [9, 22]. In addition, the amount of protein is also controlled by other factors including, the rate of gene transcription, mRNA nucleation, cytoplasmic localization, transcript stability, translational regulation, and protein degradation $[21,26,30]$. However, further studies are required to elucidate the detailed mechanism underlying the enhanced effects of the combination treatment of IFN- $\gamma$ and TNF- $\alpha$. In conclusion, our results confirm that pro-inflammatory cytokines (IFN- $\gamma$ and TNF- $\alpha$ ) can regulate the expression of i-proteasomes in porcine non-immune cells.

CONFLICT OF INTEREST. The authors declare no conflicts of interest.

ACKNOWLEDGMENTS. This study was supported by grants from the Chinese Academy of Agricultural Sciences fund for basic scientific research (no. 2008041) and the Nanchong Vocational and Technical College for basic scientific research (no. ZRA1904). 


\section{REFERENCES}

1. Abel, K., Alegria-Hartman, M. J., Rothaeusler, K., Marthas, M. and Miller, C. J. 2002. The relationship between simian immunodeficiency virus RNA levels and the mRNA levels of alpha/beta interferons (IFN-alpha/beta) and IFN-alpha/beta-inducible Mx in lymphoid tissues of rhesus macaques during acute and chronic infection. J. Virol. 76: 8433-8445. [Medline] [CrossRef]

2. An, T. Q., Tian, Z. J., He, Y. X., Xiao, Y., Jiang, Y. F., Peng, J. M., Zhou, Y. J., Liu, D. and Tong, G. Z. 2010. Porcine reproductive and respiratory syndrome virus attachment is mediated by the N-terminal domain of the sialoadhesin receptor. Vet. Microbiol. 143: 371-378. [Medline] [CrossRef]

3. Aggarwal, B. B., Eessalu, T. E. and Hass, P. E. 1985. Characterization of receptors for human tumour necrosis factor and their regulation by gamma-interferon. Nature 318: 665-667. [Medline] [CrossRef]

4. Angeles, A., Fung, G. and Luo, H. 2012. Immune and non-immune functions of the immunoproteasome. Front. Biosci. (Landmark Ed.) 17: $1904-1916$. [Medline] [CrossRef]

5. Barton, L. F., Cruz, M., Rangwala, R., Deepe, G. S. Jr. and Monaco, J. J. 2002. Regulation of immunoproteasome subunit expression in vivo following pathogenic fungal infection. J. Immunol. 169: 3046-3052. [Medline] [CrossRef]

6. Boehm, U., Klamp, T., Groot, M. and Howard, J. C. 1997. Cellular responses to interferon-gamma. Annu. Rev. Immunol. 15: 749-795. [Medline] [CrossRef]

7. Chatterjee-Kishore, M., Wright, K. L., Ting, J. P. and Stark, G. R. 2000. How Statl mediates constitutive gene expression: a complex of unphosphorylated Stat1 and IRF1 supports transcription of the LMP2 gene. EMBO J. 19: 4111-4122. [Medline] [CrossRef]

8. Choi, C., Cho, W. S., Kim, B. and Chae, C. 2002. Expression of Interferon-gamma and tumour necrosis factor-alpha in pigs experimentally infected with porcine reproductive and respiratory syndrome virus (PRRSV). J. Comp. Pathol. 127: 106-113. [Medline] [CrossRef]

9. Dalla Venezia, N., Vincent, A., Marcel, V., Catez, F. and Diaz, J. J. 2019. Emerging role of eukaryote ribosomes in translational control. Int. J. Mol. Sci. 20: 20. [Medline] [CrossRef]

10. Fairbairn, L., Kapetanovic, R., Sester, D. P. and Hume, D. A. 2011. The mononuclear phagocyte system of the pig as a model for understanding human innate immunity and disease. J. Leukoc. Biol. 89: 855-871. [Medline] [CrossRef]

11. Ferrington, D. A. and Gregerson, D. S. 2012. Immunoproteasomes: structure, function, and antigen presentation. Prog. Mol. Biol. Transl. Sci. 109: 75-112. [Medline] [CrossRef]

12. Finley, D. 2009. Recognition and processing of ubiquitin-protein conjugates by the proteasome. Annu. Rev. Biochem. 78: 477-513. [Medline] [CrossRef]

13. Früh, K. and Yang, Y. 1999. Antigen presentation by MHC class I and its regulation by interferon gamma. Curr. Opin. Immunol. 11: 76-81. [Medline] [CrossRef]

14. Gregerson, D. S., Lew, K. L., McPherson, S. W., Heuss, N. D. and Ferrington, D. A. 2006. RPE cells resist bystander killing by CTLs, but are highly susceptible to antigen-dependent CTL killing. Invest. Ophthalmol. Vis. Sci. 47: 5385-5394. [Medline] [CrossRef]

15. Hallermalm, K., Seki, K., Wei, C., Castelli, C., Rivoltini, L., Kiessling, R. and Levitskaya, J. 2001. Tumor necrosis factor-alpha induces coordinated changes in major histocompatibility class I presentation pathway, resulting in increased stability of class I complexes at the cell surface. Blood $\mathbf{9 8}$ : 1108-1115. [Medline] [CrossRef]

16. Hayashi, T. and Faustman, D. 1999. NOD mice are defective in proteasome production and activation of NF-kappaB. Mol. Cell. Biol. 19: 8646-8659. [Medline] [CrossRef]

17. Hayashi, T. and Faustman, D. 2000. Essential role of human leukocyte antigen-encoded proteasome subunits in NF-kappaB activation and prevention of tumor necrosis factor-alpha-induced apoptosis. J. Biol. Chem. 275: 5238-5247. [Medline] [CrossRef]

18. Kimura, H., Caturegli, P., Takahashi, M. and Suzuki, K. 2015. New Insights into the Function of the Immunoproteasome in Immune and Nonimmune Cells. J. Immunol. Res. 2015: 541984. [Medline] [CrossRef]

19. Liu, Q., Hu, W., Zhang, Y. L., Hu, S. P., Zhang, Z., He, X. J. and Cai, X. H. 2018. Anti-viral immune response in the lung and thymus: Molecular characterization and expression analysis of immunoproteasome subunits LMP2, LMP7 and MECL-1 in pigs. Biochem. Biophys. Res. Commun. 502: 472-478. [Medline] [CrossRef]

20. Liu, Q., Zhang, Y. L., Hu, S. P., Ma, Z. L., Gao, S. L., Sun, B., Xiao, F., Zhang, Z., Cai, X. H. and He, X. J. 2017. Expression of immunoproteasome subunits in the porcine lung: Alterations during normal and inflammatory conditions. Vet. Microbiol. 210: 134-141. [Medline] [CrossRef]

21. Martin-Perez, M. and Villén, J. 2017. Determinants and regulation of protein turnover in yeast. Cell Syst. 5: 283-294.e5. [Medline] [CrossRef]

22. Mauro, V. P. and Matsuda, D. 2016. Translation regulation by ribosomes: Increased complexity and expanded scope. RNA Biol. 13: 748-755. [Medline] [CrossRef]

23. Miller, Z., Ao, L., Kim, K. B. and Lee, W. 2013. Inhibitors of the immunoproteasome: current status and future directions. Curr. Pharm. Des. 19: 4140-4151. [Medline] [CrossRef]

24. Muchamuel, T., Basler, M., Aujay, M. A., Suzuki, E., Kalim, K. W., Lauer, C., Sylvain, C., Ring, E. R., Shields, J., Jiang, J., Shwonek, P., Parlati, F., Demo, S. D., Bennett, M. K., Kirk, C. J. and Groettrup, M. 2009. A selective inhibitor of the immunoproteasome subunit LMP7 blocks cytokine production and attenuates progression of experimental arthritis. Nat. Med. 15: 781-787. [Medline] [CrossRef]

25. Orlowski, M. and Wilk, S. 2000. Catalytic activities of the $20 \mathrm{~S}$ proteasome, a multicatalytic proteinase complex. Arch. Biochem. Biophys. 383: 1-16. [Medline] [CrossRef]

26. Radhakrishnan, A. and Green, R. 2016. Connections underlying translation and mRNA stability. J. Mol. Biol. 428: 3558-3564. [Medline] [CrossRef]

27. Rivett, A. J. and Hearn, A. R. 2004. Proteasome function in antigen presentation: immunoproteasome complexes, Peptide production, and interactions with viral proteins. Curr. Protein Pept. Sci. 5: 153-161. [Medline] [CrossRef]

28. Schoenborn, J. R. and Wilson, C. B. 2007. Regulation of interferon-gamma during innate and adaptive immune responses. Adv. Immunol. 96: 41-101. [Medline] [CrossRef]

29. Sharma, M., Sharma, S., Roy, S., Varma, S. and Bose, M. 2007. Pulmonary epithelial cells are a source of interferon-gamma in response to Mycobacterium tuberculosis infection. Immunol. Cell Biol. 85: 229-237. [Medline] [CrossRef]

30. Sonenberg, N. and Hinnebusch, A. G. 2009. Regulation of translation initiation in eukaryotes: mechanisms and biological targets. Cell 136: 731-745. [Medline] [CrossRef]

31. Theiss, A. L., Simmons, J. G., Jobin, C. and Lund, P. K. 2005. Tumor necrosis factor (TNF) alpha increases collagen accumulation and proliferation in intestinal myofibroblasts via TNF receptor 2. J. Biol. Chem. 280: 36099-36109. [Medline] [CrossRef]

32. Tsujimoto, M., Yip, Y. K. and Vilcek, J. 1986. Interferon-gamma enhances expression of cellular receptors for tumor necrosis factor. J. Immunol. 136: 2441-2444. [Medline]

33. Wajant, H., Pfizenmaier, K. and Scheurich, P. 2003. Tumor necrosis factor signaling. Cell Death Differ. 10: 45-65. [Medline] [CrossRef]

34. Zhou, N., Xing, G., Zhou, J., Jin, Y., Liang, C., Gu, J., Hu, B., Liao, M., Wang, Q. and Zhou, J. 2015. In vitro coinfection and replication of classical swine fever virus and porcine circovirus type 2 in PK15 cells. PLoS One 10: e0139457. [Medline] [CrossRef] 